Berzeidynis ber in biejen 5 sabren neu immatrifulierten Stubierenden enthält. Das $\mathfrak{B u d}$, weldes befonders für alle früberen 2 tngebörigen

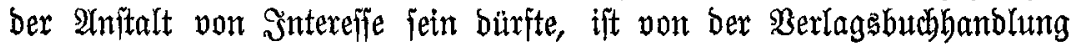
elegant gebumbent, um ben ßreis yon 2 all zu beziehen.

\title{
IV. Alatizen.
}

\section{Ergebriffe aus Kahlifhlägen.}

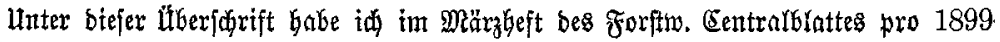

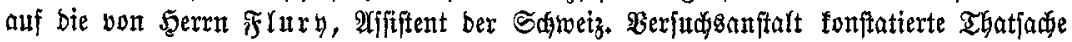
Gingeniejen, baż bie bet badung gelangenbe Solzmaffe ftets binter ber wirlid vorhanbenen nicht un=

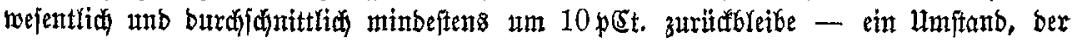

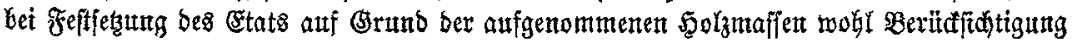
fintoet jollte.

Sal babe Gier yor alfem bie \$fflib̆t, einen in nteiner Mitteilung untergelaufenen

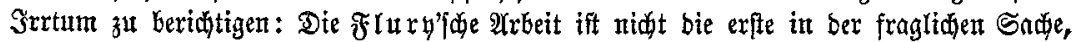

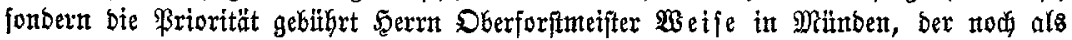

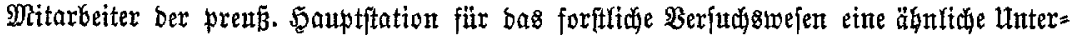

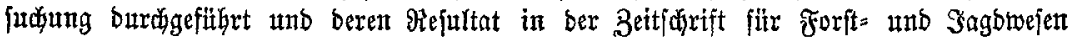

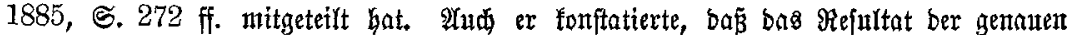
Maffenaufnahme ber Berfutfisftation um 9,1 pest. böber war, als bie yon ber Ber=

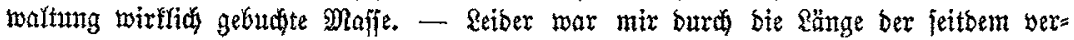

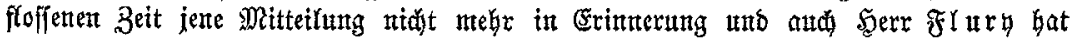
fie offenbar itberfegen, fontt würbe er beren fïfer Erwäbutung gethan Gaben.

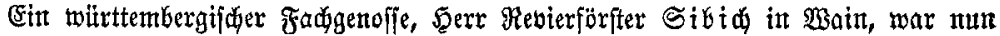
fo freunblid, mix feite Erfabrungen, bie ex - angeregt burh ben ebent bezeidneten

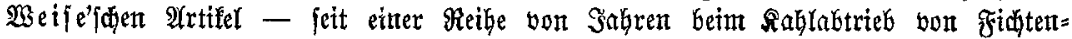

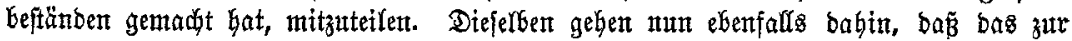

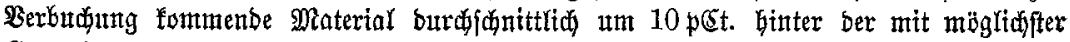

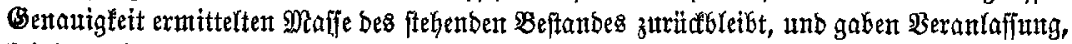

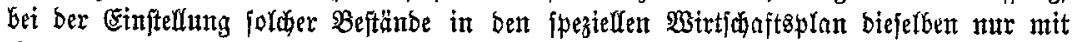

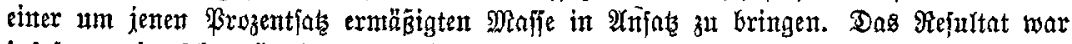
infoferne ein felle günftiges, als infolgebefien bie ouf 40,48 ha exntittelte unb ourdi 19 Rablgiebe getromene Sgolżmafje auf $21474 \mathrm{fm}$ berectinet unt unt $2135 \mathrm{fm}$, aljo auf $19339 \mathrm{fm}$ bet ber Einfteffng in ben $23 i n t i d a f t z p l a n$ rebutzert, mit betm wirflitien

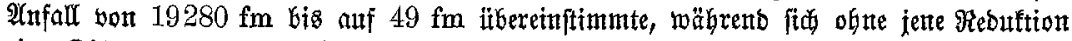
eine Differenz yon $2184 \mathrm{fm}$ ergeben bätte.

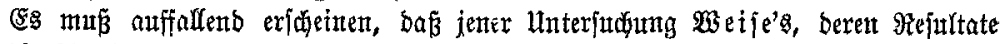

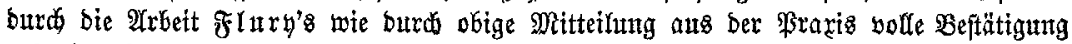

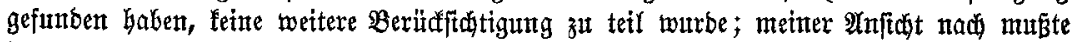

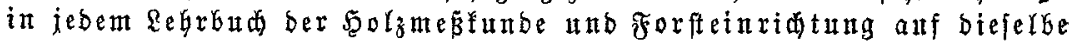

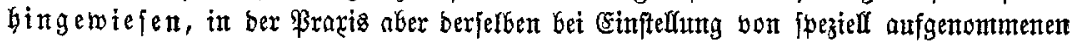

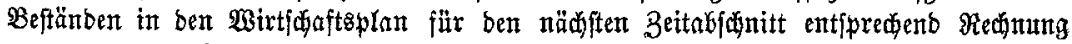
getragen werben!

Dr. Fitrft. 